\title{
Editorial
}

\section{A formação dos Terapeutas Ocupacionais e os processos de mudança nas graduações em saúde}

\author{
Elisabete Ferreira Mângia ${ }^{1}$ \\ Marta Carvalho de Almeida ${ }^{1}$ \\ Selma Lancman ${ }^{1}$
}

Desde a Constituição de 1988, indicou-se que o SUS deveria "ordenar" o processo de formação profissional na área de saúde. Essa responsabilidade, nas últimas décadas, foi compreendida como o compromisso de contribuir na orientação da formação de recursos humanos, em coerência com as diretrizes constitucionais da saúde. Assim, já há algum tempo, discute-se a necessidade do Ministério da Saúde interferir no sentido de produzir mudanças no modelo pedagógico tradicional, considerando que este é marcado pela hegemonia da abordagem biologicista do processo saúde-doença, de práticas médico-centradas e procedimento-centradas, em desacordo com as necessidades do sistema de saúde proposto e com o objetivo de avançar na construção de um modelo de atenção mais integral. Considera-se, ainda, que a formação de profissionais de saúde dissocia conhecimentos das áreas básicas e conhecimentos das áreas clínicas, incentiva à especialização precoce, é tecnicista e supervaloriza a sofisticação dos procedimentos e dos equipamentos de auxílio diagnóstico, entre outras críticas. Enfim, considerase que o modelo hegemônico da educação dos profissionais de saúde perpetua modelos tradicionais de prática em saúde (Campos et al, 2001).

$\mathrm{Na}$ base desse processo localiza-se a desarticulação entre as definições políticas dos ministérios da Saúde e da Educação, que contribui para acentuar o distanciamento entre a formação dos profissionais e as necessidades do SUS.

Diante dessa realidade parecem oportunas as recentes iniciativas, entre os setores da saúde e da educação, no sentido de promover práticas integradoras. Essas iniciativas, como a Portaria n. 2118/05 - que institui cooperação técnica entre os dois ministérios, têm sido divulgadas no contexto de um conjunto de medidas intersetoriais que visariam estimular a implantação das

${ }^{1}$ Editoras da Revista de Terapia Ocupacional da USP. Docentes do Curso de Graduação em Terapia Ocupacional da FMUSP. 
diretrizes curriculares nacionais dos cursos de graduação em saúde e fomentar processos de mudança nessas graduações, na perspectiva de aproximá-la das diretrizes da atenção integral à saúde e do SUS. Apontando o paradigma da integralidade como eixo norteador dessas mudanças, o Ministério da Saúde tem convidado aos cursos de graduação na área de saúde a engendrar novas relações de compromisso e responsabilidade entre as instituições de ensino superior e o SUS (Ministério da Saúde, SGTES, 2005).

Para além das possíveis considerações sobre a efetividade das medidas, cabe aos terapeutas ocupacionais o posicionamento claro diante delas. Há algum tempo, o processo de discussão que envolveu a definição das diretrizes curriculares da terapia ocupacional, por meio do qual se definiu o compromisso de formar profissionais considerando o sistema de saúde vigente, o trabalho em equipe e a atenção integral à saúde, apenas deu início ao desenvolvimento de temáticas importantes, inscritas no universo de relações da profissão com as políticas públicas. É tempo de aprofundá-las.

É certo que ainda consiste num grande desafio para os terapeutas ocupacionais a participação efetiva no âmbito dessas políticas. Mas é certo, também, que já podemos dar sistematização e visibilidade a experiências de ensino que mostram a possibilidade de produzir benefícios para a formação, para o exercício profissional e para os usuários do SUS, a um só tempo. Diante das perspectivas de ação coletiva que se abrirão a partir das atividades relacionadas à Década de Recursos Humanos em Saúde nas Américas, proposta para o período de 2006-2015, é possível encontrarmos boas oportunidades para mostrar que nossa atuação profissional é um fator essencial para a construção de um sistema de saúde equânime e de qualidade e para a qualidade de vida e de saúde da população brasileira.

\section{REFERÊNCIAS}

Campos, F. E.; Ferreira, J. R.; Feuerwerker, L.; Sena, R. R.; Campos, J. J. B.; Cordeiro, H.; Cordoni Jr., L. Caminhos para aproximar a formação de profissionais de saúde das necessidades da atenção básica. Rev Bras Educ Med. Rio de Janeiro, v. 25, n. 2, maio/ago, 2001.

Ministério da Saúde. Secretaria de Gestão do Trabalho e da Educação na Saúde.Política do Ministério da Saúde para o fortalecimento e ampliação dos processos de mudança na graduação em saúde: Aprender SUS. Brasília, 2005. [online] Obtido em 03/03 em www.redeunida.org.br/arquivos/ AprenderSUS-Lappis.pdf. 